\title{
Correlates of Choice of Contraceptive Methods in Pakistan
}

\author{
MANSOOR Ul HASSAN BHATTI
}

\section{INTRODUCTION}

Since 1965, contraceptive use rate has been slowly increasing in Pakistan. In 1984-85, contraceptive ever use rate was 11.8 percent and current use rate was 9.1 percent [Government of Pakistan (1986)]. These use rates increased to 20.7 percent and 11.8 percent respectively in 1990-91 [National Institute of Population Studies (1992)]. However, use rates did not increase as expected.

Pakistan's Population Welfare Programme adopted many strategies to increase the use rate of contraceptive methods but although knowledge of contraceptive methods increased to 77.9 percent [National Institute of Population Studies (1992)], use rate remained low. One of the major reasons was inadequate coverage of service delivery.

Contraceptive method of choice out of the available variety of contraceptive methods ensures continuation of use and reduces the drop-out rate [Jain (1992)]. The needs and values of individuals change over time and any one method cannot be suitable to an individual's need all the time. So if more than one method is available, and acceptor can switch over to a more suitable method of choice if the first (or previous) method of choice becomes unacceptable. Also the client's satisfaction with the method of choice is very important. Clients are best satisfied when they get the methods of their choice from a broad variety or 'mix' of contraceptive methods offered on a reliable basis [Jain (1992)].

\section{OBJECTIVES OF THE STUDY}

The major objectives of the study are:

1. To find out choices and preferences of acceptors for particular contraceptive methods;

2. to analyse the correlates of the choice of contraceptive methods; and

3. to suggest measures to provide methods of choice and to reduce the drop-out rates to the minimum.

Mansoor ul Hassan Bhatti is Senior Fellow at the National Institute of Population Studies, Islamabad.

Author's Note: The author is grateful to Mr Tewfiq Fehmi, Executive Director, National Institute of Population Studies, for encouraging him to write this paper. The author is also grateful to Dr Abdul Hakim, Director NIPS, and Mr M. N. I. Farooqui, Senior Fellow, NIPS, for providing useful comments which helped in the revision. 


\section{SOURCE OF DATA}

The issue of choice of contraceptive methods is very important, both for increasing contraceptive prevalence and for reducing drop-outs. In 1993, National Institute of Population Studies conducted a survey in the Punjab and the NWFP on "Choice of Contraceptive Methods and Drop-outs in Family Planning (CMDOS)". In this survey a stratified systematic random sample of 1929 acceptors of various contraceptive methods from Family Welfare Centres (FWCs) was selected as FWCs are major outlets of the Population Welfare Programme. The survey was restricted to the Punjab and the NWFP.

Out of the total sampled clients, only 375 or 19.4 percent could be traced and interviewed. [Bhatti and Hashmi (1993).] The present study discusses the results of that survey (CMDOS), based on the 375 sampled acceptors of family planning methods and analyses the correlates for the choice of contraceptive methods.

\section{CHARACTERISTICS USED IN THE ANALYSIS}

A client's choice of contraceptive method and use may be influenced by many factors. [Wells and Sherris (1992) and Norma (1990).] In this study, an attempt has been made to analyse and discuss the influence of the following factors on the choice of contraceptive methods and use:

1. Age;

2. parity;

3. residence;

4. knowledge of contraceptive methods; and

5. influence of interpersonal communication in contraceptive decisions.

\section{Choice of Contraceptive Methods Available in Family Welfare Centres and other Outlets in Pakistan}

In Pakistan, family planning services are provided by the public sector, nongovernmental organisations, and the private sector. In the public sector, Family Welfare Centres (FWCs) and Reproductive Health Services (RHS) Centres A and B of the Population Welfare Programme are major outlets.

The following contraceptive methods are provided for choice in Family Welfare Centres and other service delivery outlets in Pakistan:

1. IUD;

2. injection;

3. condom;

4. oral pill;

5. female sterilisation; and

6. Vaginal Methods. 
The choice of male sterilisation is not currently provided by the programme, although this choice was provided by the programme during 1965-70. [Government of Pakistan (1965).] Norplant is a new contraceptive which is still an experimental stage in Pakistan.

\section{CHOICE OF FIRST CONTRACEPTIVE METHODS}

IUD was the first choice of the largest percentage, 35 percent, of respondents. Injection was the first choice of 20 percent, condom of 14 percent, and the pill of 17 percent respondents. Female sterilisation was desired by only 10 percent, while only 4 percent preferred vaginal methods or practised rhythm or withdrawal. [Bhatti and Hashmi (1993).]

\section{Knowledge of Various Contraceptive Methods and Choice of First Method}

Choice of a contraceptive method becomes limited if clients do not have the knowledge of all contraceptive methods.

In CMDOS, since all of the respondents were acceptors of contraceptive methods, all of them had the knowledge of at least one method. However, at the time of selection of the first method, 6 percent respondents had knowledge of only one method and thus their choice was limited to only one method known to them. Of course subsequently they came to know about other methods.

\section{Age and Choice of First Contraceptive Method}

Some women, although only 5 percent, started using contraceptive methods at early age 15 to 19 . A further 22 percent started practising family planning in the next age group 20-24. A high percentage of about 58 percent started practising family planning when they were in age group 25-34, which is the prime reproductive age. It shows that in age group 20-34, about 80 percent accepted the first method. [Bhatti and Hashmi (1993).]

Table 1 shows the relationship of age to choice of first contraceptive method. In age group 15-24, 34 percent, the highest percentage of women, chose IUD; 18 percent selected injection; 25 percent chose condom; and 20 percent chose oral pill as first choice of contraceptive method whereas only one percent underwent sterilisation. No pattern of relationship of IUD acceptors and age has been observed, probably because of reported side-effects of IUD. The percentage of acceptors of condom and pill decreased as the age group rose higher while the percentage of acceptors of injection and sterilisation increased as the age group rose higher. It shows that as the age rose higher, the women preferred more effective or permanent methods. 
Table 1

Percentage of Respondents by Age and Choice of First Contraceptive Method

\begin{tabular}{lccr}
\hline \multirow{2}{*}{$\begin{array}{c}\text { Contraceptive } \\
\text { Method }\end{array}$} & \multicolumn{3}{c}{$\begin{array}{c}\text { Percent of Respondents } \\
\text { by Age Group }\end{array}$} \\
\cline { 2 - 4 } IUD & $15-24$ & $25-34$ & $35-49$ \\
Injection & 34.0 & 37.0 & 27.1 \\
Condom & 18.0 & 19.4 & 23.7 \\
Oral Pill & 25.0 & 10.6 & 10.2 \\
Sterilisation & 20.0 & 17.6 & 11.9 \\
Other Methods & 1.0 & 10.2 & 23.7 \\
\hline
\end{tabular}

\section{Children Ever Born (Ceb) and Choice of} First Contraceptive Method

About 25 percent respondents started family planning when they had 0 to 2 CEB. So it indicates that in Pakistan about 25 percent couples follow small family norms. About 30 percent started contraceptive use when they had 3 to 4 CEB. It means that 55 percent women started family planning when they had 4 children or less. Otherwise 45 percent started family planning when they had already enough children, i.e., 5 and more. [Bhatti and Hashmi (1993).]

\section{Residence and Choice of First \\ Contraceptive Method}

Table 2 shows the relationship of residence and choice of first method.

Table 2

Percentage of Respondents by Choice of First Contraceptive Method and by Residence

\begin{tabular}{lcc}
\hline \multirow{2}{*}{ Contraceptive Method } & \multicolumn{2}{c}{ Residence } \\
\cline { 2 - 3 } & Urban & Rural \\
\hline IUD & 51.5 & 48.5 \\
Injection & 36.5 & 63.5 \\
Condom & 61.1 & 38.9 \\
Oral Pill & 47.7 & 52.3 \\
Sterilisation & 29.7 & 70.3 \\
Other Methods & 71.4 & 28.6 \\
Number of Women & 177 & 198 \\
\hline
\end{tabular}


It is observed that in urban areas most women chose IUD, condom or another method as the first method of choice whereas in rural areas most women chose injection, pill or sterilisation. It may be mentioned here that the results in case of oral pills may be interpreted with caution due to the supply problems of this method to certain FWCs.

\section{Influence of Interpersonal Communication in Contraceptive Decision for Choice of First Contraceptive Method}

Advice from Family Welfare Worker (FWW) in charge of FWC, other acceptors, relatives, and friends was the major factor which influenced most of the women for choosing the first contraceptive method. In 79 percent cases, acceptors chose the method on the advice of others, whereas only in 21 percent cases, acceptors decided the choice on their own. Family Welfare Worker (FWW) was found as the key person influencing the decisions.

Specifically 48 percent of IUD acceptors, 45 percent of acceptors of injection, 41 percent of condom acceptors, 66 percent of oral pill acceptors, and 41 percent of female sterilisation acceptors chose methods on the recommendation of FWW [Bhatti and Hashmi (1993)].

This shows that women mainly relied on the advice of FWW for the choice of a suitable contraceptive method rather than taking the decision themselves as to the choice on the basis of merit and suitability of a contraceptive method.

However, in case of female surgery, although 41 percent women accepted the method on the advice of FWW, yet other 35 percent took the decision of choice on their own on merit, considering the method as more effective. Although this maintains the importance of the interpersonal relation between the FWW and the clients, yet in the case of female sterilisation it shows that a high percentage of women did not just rely on FWW for the decision. [Bhatti and Hashmi (1993)].

The second major influence was that of other acceptors, and in that respect 17 percent acceptors were influenced by other users. This shows the importance of the satisfied users. The third largest group comprising 14 percent of women were persuaded by relatives and friends. [Bhatti and Hashmi (1993).]

\section{Change in Choice of Contraceptive Methods}

After practising first method for some time, 45 percent women interchanged for other methods as second methods of choice, 15 percent interchanged for third methods, 3 percent changed to a fourth method, and a negligible percentage changed to a fifth method. It shows that acceptors were either not satisfied with the first method of choice or a first method was not available. Table 3 shows the details of changes of choice from a first method to the method in current use. 
Table 3

Percentage of Respondents by Choice of First Contraceptive Method, Ever Used and Currently Used

\begin{tabular}{lcccccc}
\hline & \multicolumn{7}{c}{ Percent Respondents by Contraceptive Method } \\
\cline { 2 - 7 } $\begin{array}{l}\text { Contraceptive } \\
\text { Method }\end{array}$ & $\begin{array}{c}\text { First } \\
\text { Method }\end{array}$ & $\begin{array}{c}\text { Changed } \\
\text { from Other } \\
\text { Methods }\end{array}$ & $\begin{array}{c}\text { Ever } \\
\text { Use } \\
\text { d }\end{array}$ & $\begin{array}{c}\text { Changed } \\
\text { to Other } \\
\text { Methods }\end{array}$ & Dropped & $\begin{array}{c}\text { Currently } \\
\text { Used }\end{array}$ \\
\hline IUD & 34.7 & 20.8 & 55.5 & 13.3 & 11.2 & 30.9 \\
Injection & 19.7 & 12.3 & 32.0 & 15.7 & 7.5 & 8.8 \\
Condom & 14.4 & 10.4 & 24.8 & 11.5 & 5.1 & 8.3 \\
Oral Pill & 17.3 & 7.2 & 24.5 & 17.1 & 2.7 & 4.8 \\
Sterilisation & 9.9 & 7.5 & 17.3 & 0.0 & 0.0 & 17.3 \\
Other Methods & 4.0 & 5.3 & 9.3 & 5.9 & 0.3 & 3.2 \\
Number of & & & & & & \\
Women & 375 & & 375 & & 100 & 275 \\
\hline
\end{tabular}

IUD was the first contraceptive method of about 35 percent women whereas a little less than 21 percent other women accepted it as a second or a subsequent method. Thus IUD ever users rose to 55 percent. There were 13 percent women who shifted to other methods and 11 percent who left the use of any method altogether. So 31 percent women were found to be the current users.

Injection, Condom, and oral pill were originally accepted by 20 percent, 14 percent, and 17 percent women, respectively, but the current users were reduced to 9 percent, 8 percent, and 5 percent, respectively. Sterilisation as first method was used by 10 percent women, but 7 percent more underwent sterilisation after dropping other methods, and thus the current use of sterilisation was 17 percent.

Side-effects and non-availability of supplies were the major reasons to change any method.

\section{Choice of Ever Use of Contraception}

The choice of ever use of IUD was found to be the highest as far as the acceptance of a method from FWCs is concerned. The choice of ever use of injection was the second highest. The choice of ever use of pill and condom was equal and was third in rank. The choice of female sterilisation was 17 percent. [Bhatti and Hashmi (1993).]

Only 3 percent acceptors ever used vaginal methods whereas 6 percent acceptors practised other methods, i.e., rhythm or withdrawal. 
In the national sample of PDHS 1990-91, it was observed that more women ever-used rhythm, condom or pill as compared to IUD or injection, probably due to the fact that IUD and injection were not available to the majority of acceptors.

\section{Ever Use and Age}

Choice of contraceptive methods varied with age. The ever use of IUD in age group 20-24 was 56 percent. It rose in age group 25-29 to 61 percent, and in age group 30-34 to 63 percent, but beyond 34 years the percentage gradually decreased. Probably as the age rose beyond 34, women preferred a permanent method. The ever use of female sterilisation increased with age, as in higher age more women preferred a permanent method. There is no pattern of ever use of injection, condom, and pill, probably because of interruption in supplies. [Bhatti and Hashmi (1993).]

\section{Influence of Interpersonal Communication on Choice of Ever Use of Contraceptive Methods}

In the case of ever use of contraceptive methods also, the major reason for the choice of any method, except vaginal methods, rhythm, and withdrawal, was that FWW recommended that method. The second major reason to choose IUD, injection, condom, and pill was the recommendation of other acceptors, friends or relatives. In case of female sterilisation, 39 percent acceptors decided for surgery on the advice of FWW and 35 percent went for an operation, taking their own decision and considering the method as the most effective. [Bhatti and Hashmi (1993).]

\section{Choice of Current Use of Contraceptive Methods}

Total current use for this group was found to be 73 percent, and the rest, 27 percent, had dropped out.

Current use of IUD was the highest. It was 31 percent. The current use of female sterilisation was 17 percent. It means women preferred more effective methods in current use. The current use of injection, condom, and pill was 9, 8 , and 5 percent, respectively. The current use of other methods was only 3 percent. [Bhatti and Hashmi (1993).]

The main reasons for dropping the use of any contraceptive method were the wish to have more children, the side-effects of contraceptive methods, and the discontinuation of supplies, specially for injection.

\section{Current Use and Age}

Table 4 explains the relationship of current users with their current age. 
Table 4

Percent of Current Users by Specific Method and by Current Age

\begin{tabular}{lcccc}
\hline Contraceptive & & \multicolumn{3}{c}{ Current Age } \\
\cline { 2 - 5 } \multicolumn{1}{c}{ Method } & All & $20-29$ & $30-39$ & $40-49$ \\
\hline IUD & 42.2 & 47.7 & 42.1 & 31.8 \\
Injection & 12.0 & 18.6 & 9.0 & $9.1^{*}$ \\
Condom & 11.3 & 16.3 & 9.7 & $6.8^{*}$ \\
Oral Pill & 6.5 & 5.8 & 6.9 & $6.8^{*}$ \\
Female Sterilisation & 23.6 & 7.0 & 29.0 & 38.6 \\
Other Methods & 4.4 & $4.7^{*}$ & 3.4 & $6.8^{*}$ \\
Number of Women & 275 & 86 & 145 & 44 \\
\hline
\end{tabular}

*Frequencies less than 5 .

The current use of IUD, injection and condom decreased as age increased, probably women shifted to a permanent method of sterilisation in current use when they attained higher ages. For similar reason, current use of female sterilisation increased as age increased.

\section{Influence of Number of Living Children on \\ Choice of Current Contraceptive Method}

Table 5 shows the relationship of current users with the number of living children.

Table 5

Percent of Current Users by Specific Method and by Living Children

\begin{tabular}{lcccr}
\hline Contraceptive & \multicolumn{4}{c}{ Living Children } \\
\cline { 2 - 5 } \multicolumn{1}{c}{ Method } & $1-2$ & $3-4$ & $5-6$ & $7-11$ \\
\hline IUD & 61.3 & 44.9 & 39.1 & 32.2 \\
Injection & 12.9 & 16.3 & 12.6 & 3.4 \\
Condom & 19.4 & 13.3 & 10.3 & 5.1 \\
Oral Pill & $0.0^{*}$ & 8.2 & 8.0 & 5.1 \\
Female Sterilisation & $3.2^{*}$ & 11.2 & 26.4 & 50.8 \\
Other Methods & $3.2^{*}$ & 6.1 & $3.4^{*}$ & 3.4 \\
\hline Number of Women & 31 & 98 & 87 & 59 \\
\hline
\end{tabular}

*Frequencies less than 5 .

Current use of IUD, condom, and oral pill decreased as the number of living children increased. Current use of sterilisation increased as the number of living children increased. 


\section{Interpersonal Communication and Choice of Contraceptive Method in Current Use}

Table 6 shows the influence of interpersonal communication in choosing a method in current use.

Table 6

Percentage of Current Users by Specific Method and by Reasons of Current Use

\begin{tabular}{lccccc}
\hline & \multicolumn{5}{c}{ Reasons for Current Use } \\
\cline { 2 - 5 } \begin{tabular}{l} 
Contraceptive \\
\multicolumn{1}{c}{ Method }
\end{tabular} & FWh & $\begin{array}{c}\text { Other } \\
\text { Acceptor }\end{array}$ & $\begin{array}{c}\text { Someone } \\
\text { Else }\end{array}$ & $\begin{array}{c}\text { Method } \\
\text { Effective }\end{array}$ & $\begin{array}{c}\text { Other } \\
\text { Reasons }\end{array}$ \\
\hline IUD & 59.5 & 13.8 & 12.1 & 6.9 & 7.8 \\
Injection & 51.5 & 24.2 & 6.1 & 3.0 & 15.2 \\
Condom & 51.6 & 6.5 & 22.6 & 6.5 & 12.2 \\
Oral Pill & 83.3 & $0.0^{*}$ & $0.0^{*}$ & $0.0^{*}$ & 16.7 \\
Sterilisation & 36.9 & 6.2 & 10.8 & 35.4 & 10.8 \\
Other Methods & $16.7^{*}$ & $0.0^{*}$ & $25.0^{*}$ & $0.0^{*}$ & $58.3^{*}$ \\
\hline
\end{tabular}

*Frequencies less than 5 .

It is observed that in case of current use also, the major reason to choose IUD, injection, condom, and oral pill was the recommendation or advice of FWW. The second reason to choose a contraceptive method, except oral pill and female sterilisation, was the recommendation of other acceptors or someone else.

\section{CONCLUSIONS AND RECOMMENDATIONS}

Pakistan's population welfare programme provided only a limited choice of contraceptive methods. Choice of male sterilisation was not currently provided by the programme and the choice of vaginal methods such as diaphragm, jelly, durafoam, and emko was almost not available. It is suggested that male sterilisation and vaginal methods should be made available and promoted as method of choice. In fact these methods were provided during 1965-70 [Government of Pakistan (1965)].

The following was the priority order for choice of methods and trends of shifts from the choice of first method to the choice of method in current use:

$\begin{array}{lllll}\text { First Method } & \text { IUD } & \text { Injection } & \text { Pill } & \text { Condom } \\ \text { Ever Use } & \text { IUD } & \text { Injection } & \text { Condom/ } & \text { Pill } \\ \text { Current Use } & \text { IUD } & \text { Sterilisation } & \text { Injection } & \text { Condom }\end{array}$

It is observed that IUD was the most accepted method whether it was the first choice, change in choice, or the choice in current use. Injection ranked next to IUD as first method while in current use, female sterilisation was the choice of the highest percentage of women next to IUD. 
The following are the correlates of choice of contraceptive methods:

1. Age;

2. parity;

3. residence;

4. knowledge of contraceptive methods; and

5. interpersonal communication such as advice of FWW, other acceptors, friends or relatives.

FWWs had a strong influence on acceptors in decision-making. It will be worthwhile to make full use of their services as promoters of family planning. Besides, satisfied users can play a vital role in enhancing contraceptive use.

Method selection was not really a free choice. Women mostly depended on others' advice to accept a particular contraceptive method and use it. The choice of particular contraceptive method should be freely made, on the basis of the merits of a method.

Choice of contraceptive methods varied with age. It was observed that as age rose higher, women preferred more effective or permanent methods.

A total of 27 percent acceptors dropped out. The major reason for dropping out was the wish to have more children; other reasons for dropping out were the side-effects of contraceptive use and discontinuation of supplies. So the quality of services by FWCs should be improved.

\section{REFERENCES}

Bhatti, Mansoor ul Hassan, and Sultan S. Hashmi (1993) Choice System of Contraceptive Methods and Drop-out in Family Planning. Islamabad: National Institute of Population Studies. (First Report.)

Jain, Anrudh K. (1992) Managing Quality of Care in Population Programmes. USA.

National Institute of Population Studies (1992) Pakistan Demographic and Health Survey 1990-91. IRD/Macro International Inc.

Norma, Abdullah (1990) Selection, Change and Discontinuation of Contraceptive Methods in Trinidad and Tobago. Demographic and Health Surveys Further Analysis Series Number 4. Institute of Resource Development/Macro, Inc.

Pakistan, Government of (1965) Family Planning Scheme for Pakistan 1965-70. Islamabad: Ministry of Health, Labour and Social Welfare.

Pakistan, Government of (1986) Pakistan Contraceptive Prevalence Survey 1984-85. Islamabad: Ministry of Planning and Development, Population Welfare Division.

Wells, Elisa, and Jacqueline Sherris (1992) A Client's Choice. Populi 19:3 September. 